\title{
Analysis of determinants of severity levels of childhood anemia in Bangladesh using a proportional odds model
}

\author{
Sohani Afroja, Md Rasel Kabir*, Md Akhtarul Islam \\ Statistics Discipline, Khulna University, Khulna, 9208, Bangladesh
}

\section{A R T I C L E I N F O}

\section{Keywords:}

Anemia

Determinants

Ordinal logistic regression

Severity levels

\begin{abstract}
A B S T R A C T
Background: Anemia is an important risk factor for the health of children as it leads to delayed growth and has long term impacts on neurodevelopment and behavior which causes child morbidity and mortality. Though the rate of severe anemia is almost ignorable in Bangladesh, the overall prevalence of anemia is still very high. Thus this study designed to identify determinants of severity levels of anemia among children aged 6-59 months from the nationally representative 2011 Bangladesh Demographic and Health Survey (BDHS).

Method: A total of 2188 children aged 6-59 months with complete information on the selected predictors were finally identified from data of this cross sectional survey. Proportional odds model was applied to assess the impacts of determinant on severity level of anemia.

Results: Among 2188 children sampled, 24.8\%, 32.3\% and 42.9\% were severely or moderately anemic, mildly anemic, and non-anemic, respectively. Out of children who resided in urban areas, $27.1 \%$ were mildly anemic, and $21.1 \%$ were severely or moderately anemic. Stunting, division, wealth index, mother's anemia status, age of child, water facility and mother's body mass index were found to be statistically significant determinants of severity levels of childhood anemia. Test of parallelism showed that the odds ratios were constant across all cutoff points of childhood anemia status at $5 \%$ level.

Conclusions: In summary, our analysis highlights concerning continuing public health challenge presented by anemia in Bangladesh. This study explores the factors associated with the severity level anemia.
\end{abstract}

\section{Introduction}

Anemia defined as low hemoglobin concentrations in blood, is a major public health concerns throughout the world and is a special concern in many developing countries where the incidence and severity of anemia in certain populations is very high. This fundamental health issue is affecting the health, quality of life, and working capacity in billions of people all over the world. ${ }^{1}$ Though the global mean hemoglobin is increasing and the anemia prevalence is decreasing but at slower rate, there was also an opposite scenario in south asia and central and west Africa. ${ }^{2,3}$ Severe anemia is a significant cause of childhood mortality ${ }^{4}$ high prevalence of anemia and its consequences on children's health especially for their growth and development. ${ }^{5}$ Anemia affects almost 1.62 billion people (95\% CI: $1.50-1.74$ billion), which corresponds to $24.8 \%$ of the population (95\% CI: $22.9-26.7 \%)^{6}$ in the whole world. The highest prevalence is in preschool-age children (47.4\%, 95\% CI: 45.7-49.1), and the lowest prevalence is in men $(12.7 \% \text {, 95\% CI: } 8.6-16.9 \%)^{7}$ Survey conducted by the Nutritional Surveillance Project (NSP) of Helen Keller International (HKI) in collaboration with the Institute of Public Health Nutrition (IPHN) in 2004 shows that $68 \%$ of children under five years of age are anemic, with the highest prevalence among those 6-11 months old (92\%). So, it is a significant public health problem in Bangladesh, and its devastating effects on health, physical and mental productivity affect quality of life, particularly among the poor, and translate into significant economic losses for individuals as well as for the country. ${ }^{8}$

Ensure healthy lives and promote wellbeing for all at all ages is the third goal among the 17 Sustainable Development Goals (SDGs) ${ }^{9}$ followed by which investments in children was recognized as a central building block of the SDGs' sustainable and equitable growth agenda in Third Financing for Development Conference. On the of the suggested health targets described in the issue of child survival and health development is to end preventable newborn deaths by reducing, in all countries, the newborn mortality rate to 12 or less deaths per 1000 live births and child deaths by reducing, in all countries, the under-five mortality rate to 25 or less deaths per 1000 live births by $2030 .^{10}$ Though Millennium Development Goals (MDGs) attainment in Bangladesh has been quite impressive (under-5 mortality rate (per 1000

\footnotetext{
* Corresponding author. 2920 7th Street East, Saskatoon, Saskatchewan, S7H1A8, Canada.

E-mail address: raselsh023@yahoo.com (M.R. Kabir).
} 
live births) and infant mortality rate (per 1000 live births) are 46 (BDHS 2014, NIPORT) and 38 (BDHS 2014, NIPORT)) respectively, whereas the targets by 2015 were 48 and 31), it is still challenging for her to reduce the prevalence of anemia and lessen the preventable deaths of newborns and under- 5 children to at least 12 and 25 per 1000 live births. ${ }^{11}$ Reduction the anemia prevalence, one of the leading causes of child death, may contribute a lot to achieve this goal.

Anemia is a condition in which the number of red blood cells or their oxygen-carrying capacity is insufficient to meet phycologic needs, which vary by age, sex, altitude, smoking, and pregnancy status. This often unrecognized and consequently undertreated condition impairs the delivery of oxygen to tissues and can manifest clinically as fatigue or lethargy, depression, and impaired cognitive function. ${ }^{12}$ Maternal anemia during pregnancy is an independent risk factor for low-birthweight infants and preterm delivery. ${ }^{13}$ Although Iron deficiency is the most common cause of anemia globally, other conditions, such as folate, vitamin $\mathrm{B}_{12}$ and vitamin $\mathrm{A}$ deficiency, chronic inflammation, parasitic infections and inherited disorders can all cause anemia. In its severe form, it is associated with fatigue, weakness, dizziness and drowsiness. As a result, pregnant women and children are particularly vulnerable. ${ }^{14,15}$

In addition, several studies have shown a clear correlation between anemia and a series of determinants, such as division, ${ }^{16}$ type of residence, low educational level of the mother, ${ }^{17}$ low educational level of the father, ${ }^{18}$ mother's age, mother's BMI, low per capita family income, ${ }^{19}$ water facilities, ${ }^{20}$ toilet facilities, Number of $\mathrm{HH}$ members, Number of under-5 children, mother's anemia level, breastfeeding status, sex of child, ${ }^{20}$ age of child, birth order, had diarrhea recently, had fever recently, stunting, under-weight and wasting. ${ }^{19}$

Binary logistic regression and linear regression are the frequent approaches used in most studies to investigate factors that influence childhood anemia. For example, many studies ${ }^{21-24}$ use a binary logistic model and some $e^{25,26}$ use a Gaussian model. When a binary logistic model is used, researcher consider childhood anemia as a binary response variable (non-anemic [hemoglobin $\mathrm{Hb}>11 \mathrm{~g} / \mathrm{dL}$ ] or anemic $[\mathrm{Hb}<11 \mathrm{~g} / \mathrm{dL}])$, and a Gaussian model is used considering the childhood $\mathrm{Hb}$ level as continuous a response. Nevertheless, the interest in analyzing the severity of the disease and the corresponding risk factors is of epidemiological importance. ${ }^{27,28}$ In cases where childhood anemia can be considered as an ordered response (ie, non-anemia $[\mathrm{Hb} \geq 11 \mathrm{~g} / \mathrm{dL}]$, mild anemia $[10.9 \mathrm{~g} / \mathrm{dL} \leq \mathrm{Hb} \leq 10 \mathrm{~g} / \mathrm{dL}]$, moderate anemia $[9.9 \mathrm{~g} / \mathrm{dL} \leq \mathrm{Hb} \leq 7.0 \mathrm{~g} / \mathrm{dL}]$, and severe anemia $[\mathrm{Hb}<7.0 \mathrm{~g} /$ $\mathrm{dL}]$ ), a multinomial ordered model is appropriate. To our knowledge, no study in Bangladesh has employed the use of multinomial ordered outcome model for childhood anemia. The use of a multinomial ordered outcome model may help to identify children at the greatest risk to anemia, which is important when resources are inadequate. In this study, we performed a comprehensive investigation of childhood anemia and its determinants among the under 5 years children in Bangladesh. Our aim is to estimate the national prevalence of anemia by severity level and explore the factors associated with the direction of severity level as a basis for prevention and control programs. Moreover, the study can help public health policymakers determine priorities for intervention.

\section{Methods and materials}

\subsection{Data source and sampling design}

This current study used the nationally representative (latest survey with anemia information) from Bangladesh Demographic and Health Survey (BDHS 2011) data. We used this data as a secondary source of information. This cross sectional survey was conducted under the authority of the National Institute for Population Research and Training (NIPORT) of the Ministry of Health and Family Welfare, Government of the People's Republic of Bangladesh. ${ }^{29}$ The main objective of this periodic survey was to serve population and health data for policy makers, program managers, and the research community as well as monitor the progress in those sectors. Enumeration areas (EAs) from the population census 2011 were primary sampling units (PSUs) for this survey, with PSUs designed to produce separate estimates of key indicators for each of the seven divisions such as Dhaka, Chittagong, Rajshahi, Rangpur, Khulna, Barisal and Sylhet. Data collection took place over a five month period from July 8 to December 27, 2011. Based on two-staged stratified and clustered sample of households. About 120 households from Upazilla (sub-district) were considered as enumeration areas (EA). These EAs were used as the primary sampling units (PSUs) for the survey and these were selected with probability proportional to the size. In the second stage of sampling, a systematic sample of 30 households on average was selected per EA to provide statistically reliable estimates of key demographic and health variables (Bangladesh Demographic and Health Survey, 2011).

\subsection{Variables included in the model}

The outcome variable in this study was anemia status of children aged 6-59 months, categorized into three: not anemic, mild and severe or moderate. Anemia status was determined on hemoglobin concentration in blood adjusted to altitude. Adjusted concentration $10.0-10.9 \mathrm{~g} / \mathrm{dl}$ was considered as mild anemia, 7.0-9.9 g/dl as moderate anemia and less than $7.0 \mathrm{~g} / \mathrm{dl}$ as severe anemia. ${ }^{29}$ After selecting only children from de jure households and excluding children with missing information on hemoglobin or any of the other key predictors considered in this study, 2188 children of 6-59 months aged from the 2011 survey were retained for the final analysis.

This study tried to include the most important expected determinants of anemia from various literature reviews, ${ }^{30,31}$ and their theoretical justification from the source of data. ${ }^{31}$ In our study we have used the explanatory variables at individual and household levels included Division, Type of residence, Mother's educational status, Father's education status, Mothers Age, Mother's BMI, Wealth Index, Water facility, Toilet facility, Mother's anemia level, Breastfeeding status, Age of child, Had Diarrhea recently, Had fever recently, Stunting.

\section{Method of analysis}

Ordinal logistic regression model was employed because of child anemia status is ordered. Specifically, proportional odds model (POM) was employed because of the following appealing features: (a) it is invariant under several categories as only the signs of the regression coefficients change when the coding of the response variable are inverted $^{32,33}$; (b) it is invariant under collapsibility of the ordered categories as the regression coefficients do not change when response categories are collapsed or the category definitions are changed ${ }^{34}$; and (c) it produces the most easily interpretable regression coefficients as exp $(-\beta)$ is the homogenous odds ratio (OR) over all cut-off points summarizing the effects of the explanatory variables on the response variable in a single frequently used measure. ${ }^{32}$ The POM for the categorical variable $\mathrm{Y}$ with $\mathrm{C}$ ordered categories a collection of $\mathrm{P}$ explanatory variables for the $l^{\text {th }}$ subject

$X_{l}=\left(x_{i l}, x_{2 l}, \ldots, x_{p l}\right), l=1,2, \ldots, n$ is given as;

$\log i t\left[Y_{l} \leq i \mid x_{l}\right]=\log \left[\frac{\pi_{i}\left(X_{l}\right)}{1-\pi_{i}\left(X_{l}\right)}\right]$

$=\alpha_{i}-\beta_{1} x_{1 l}-\ldots-\beta_{p} x_{p l}$

$=\alpha_{i}-X_{l}^{\prime} \beta$ for $\mathrm{i}=1,2, \ldots, \mathrm{c}-1 ; 1=1,2, \ldots, \mathrm{n}$

Where, sis the regression parameters associated with $X_{l}$ and $\alpha_{i}$ is the intercept for the cumulative logit, $\pi_{i}\left(X_{l}\right)=\operatorname{Pr}\left[Y_{l} \leq i \mid x_{l}\right]$ and $\beta$ is a column vector of $\mathrm{P}$ regression coefficients and $\alpha_{i}$ is ith intercept 
Table 1

Association of anemia status with different covariates.

\begin{tabular}{|c|c|c|c|c|c|c|c|}
\hline \multirow[t]{2}{*}{ Variable } & \multirow[t]{2}{*}{ Measurement Scale } & \multirow[t]{2}{*}{ Categories } & \multicolumn{3}{|l|}{ Child anemic status } & \multirow[t]{2}{*}{$\chi^{2}$ (P-value) } & \multirow[t]{2}{*}{ Gamma (P-value) } \\
\hline & & & Not anemic \% (n) & Mild \% (n) & Severe or moderate $\%(n)$ & & \\
\hline \multirow[t]{7}{*}{ Division } & \multirow[t]{7}{*}{ Nominal } & Dhaka & $52.6(191)$ & 27.3(99) & $20.1(73)$ & \multirow[t]{7}{*}{$20.583(0.057)^{* *}$} & \multirow[t]{7}{*}{-} \\
\hline & & Chittagong & $48.3(196)$ & $28.6(116)$ & $23.2(94)$ & & \\
\hline & & Barisal & $40.4(95)$ & $33.2(78)$ & $26.4(62)$ & & \\
\hline & & Khulna & $45.0(113)$ & $33.9(85)$ & 21.1(53) & & \\
\hline & & Rajshahi & $51.7(139)$ & $29.0(78)$ & $19.3(52)$ & & \\
\hline & & Rangpur & $42.1(125)$ & $32.7(97)$ & $25.3(75)$ & & \\
\hline & & Sylhet & $52.3(192)$ & $25.6(94)$ & $22.1(81)$ & & \\
\hline \multirow[t]{2}{*}{ Type of residence } & \multirow[t]{2}{*}{ Nominal } & Rural & $46.4(708)$ & $30.6(467)$ & $23.0(350)$ & \multirow[t]{2}{*}{$5.291(0.071)^{* *}$} & \multirow[t]{2}{*}{ - } \\
\hline & & Urban & $51.7(343)$ & $27.1(180)$ & $21.1(140)$ & & \\
\hline \multirow[t]{4}{*}{ Mother's educational status } & \multirow[t]{4}{*}{ Ordinal } & No education & $46.5(193)$ & 28.7(119) & $24.8(103)$ & \multirow[t]{4}{*}{ - } & \multirow[t]{4}{*}{$-0.083(0.004)^{* *}$} \\
\hline & & Primary & $45.4(322)$ & $30.6(217)$ & $24.0(170)$ & & \\
\hline & & Secondary & $48.3(439)$ & $30.6(278)$ & $21.1(192)$ & & \\
\hline & & Higher & $62.6(97)$ & $21.3(33)$ & $16.1(25)$ & & \\
\hline Father's educational status & Ordinal & No education & $48.0(297)$ & $31.0(192)$ & $21.0(130)$ & _- & $-0.066(0.014)^{* *}$ \\
\hline & & Primary & $43.5(289)$ & $29.4(195)$ & $27.1(180)$ & & \\
\hline & & Secondary & $47.7(295)$ & $30.0(186)$ & $22.3(138)$ & & \\
\hline & & Higher & $59.4(170)$ & $25.9(74)$ & $14.7(42)$ & & \\
\hline Mother's age & Ordinal & Less than 20 years & $36.8(146)$ & $32.7(130)$ & $30.5(121)$ & _- & $-0.140(0.000)^{*}$ \\
\hline & & $20-29$ years & $50.2(618)$ & $28.7(353)$ & $21.2(261)$ & & \\
\hline & & $>=30$ years & $51.3(287)$ & $29.3(164)$ & $19.3(108)$ & & \\
\hline Mother's body mass index & Nominal & Normal & $48.9(602)$ & $31.0(382)$ & $20.1(248)$ & $39.257(0.000)^{* * *}$ & _- \\
\hline & & Under weight & $41.7(267)$ & $28.4(182)$ & $30.0(192)$ & & \\
\hline & & Overweight & $57.8(182)$ & $26.3(83)$ & $15.9(50)$ & & \\
\hline Wealth index & Ordinal & Poor & $41.3(386)$ & $31.6(295)$ & $27.1(253)$ & _- & $-0.186(0.000)^{* *}$ \\
\hline & & Middle & $48.2(189)$ & $31.6(124)$ & $20.2(79)$ & & \\
\hline & & Rich & $55.2(476)$ & $26.5(228)$ & $18.3(158)$ & & \\
\hline Water facility & Nominal & Improved & $48.9(959)$ & $29.1(571)$ & $22.0(432)$ & $5.423(0.066)^{* *}$ & _- \\
\hline & & Non-improved & $40.7(92)$ & $33.6(76)$ & $25.7(58)$ & & \\
\hline Toilet facility & Nominal & Improved & $51.1(582)$ & $28.9(330)$ & $20.0(228)$ & $10.921(0.00)^{* *}$ & _- \\
\hline & & Non-improved & $44.8(469)$ & $30.2(317)$ & $25.0(262)$ & & \\
\hline Mother's anemia level & Nominal & Not anemic & $54.7(684)$ & $26.9(336)$ & $18.4(230)$ & $55.045(0.000)^{* * *}$ & _ \\
\hline & & Anemic & $39.1(367)$ & $33.2(311)$ & $27.7(260)$ & & \\
\hline Breastfeeding Status & Nominal & No & $59.5(455)$ & $26.0(199)$ & $14.5(111)$ & $69.751(0.000)^{* *}$ & _- \\
\hline & & Yes & $41.9(596)$ & $31.5(448)$ & $26.6(379)$ & & \\
\hline Sex of child & Nominal & Male & $46.9(526)$ & 29.1(326) & $24.1(270)$ & $3.711(0.156)$ & _ \\
\hline & & Female & $49.2(525)$ & $30.1(321)$ & $20.6(220)$ & & \\
\hline Age of Child & Ordinal & 6-24 months & $29.6(221)$ & $32.7(244)$ & $37.8(282)$ & _- & $-0.399(0.00)^{* *}$ \\
\hline & & 24-36 months & $52.8(238)$ & $30.6(138)$ & $16.6(75)$ & & \\
\hline & & 36-59 months & $59.8(592)$ & $26.8(265)$ & $13.4(133)$ & & \\
\hline Birth order & Ordinal & 1st birth & $48.0(363)$ & $29.8(225)$ & $22.2(168)$ & _- & $0.018(0.556)$ \\
\hline & & $2-3$ & $49.0(481)$ & $29.3(288)$ & $21.7(213)$ & & \\
\hline & & Above & $46.0(207)$ & $29.8(134)$ & $24.2(109)$ & & \\
\hline Had diarrhea recently & Nominal & No & $48.4(999)$ & $29.7(614)$ & $21.9(451)$ & $6.221(0.045)^{* *}$ & _- \\
\hline & & Yes & $41.9(52)$ & $26.6(33)$ & $31.5(39)$ & & \\
\hline Had fever recently & Nominal & No & $50.6(664)$ & $28.4(372)$ & $21.0(276)$ & $8.864(0.012)^{* *}$ & - \\
\hline & & Yes & $44.2(387)$ & $31.4(275)$ & $24.4(214)$ & & \\
\hline Stunting & Nominal & No & $51.7(661)$ & $27.6(353)$ & $20.7(264)$ & $16.785(0.000)^{* * *}$ & _ \\
\hline & & Yes & $42.9(390)$ & $32.3(294)$ & $24.8(226)$ & & \\
\hline Underweight & Nominal & No & $48.9(664)$ & $30.0(497)$ & $21.1(287)$ & $3.287(0.193)$ & _- \\
\hline & & Yes & $46.6(387)$ & $28.9(240)$ & $24.5(203)$ & & \\
\hline Wasting & Nominal & No & $47.8(871)$ & $30.1(549)$ & $22.1(402)$ & $1.814(0.404)$ & _- \\
\hline & & Yes & $49.2(180)$ & $26.8(98)$ & $24.0(88)$ & & \\
\hline
\end{tabular}

coefficient. Note that under PO, it is assumed that the effect of each explanatory variable is the same for any cumulative logit. We can describe the effects by comparing the cumulative probabilities rather than using odds ratio. A non-significant chi-square test of parallelism was taken as evidence that the logit surfaces are parallel and that the odds ratios can be interpreted as constant across all possible cut-off points of the outcome variable. In our study we measured the dependent variable anemia status in ordinal scale. The relationship between selected explanatory variables and anemia status has been analyzed in two ways such as bivariate and multivariate analysis respectively. Gamma measure is the most common measures of association for ordinal variables are based on the classification of pairs of observations as concordant or discordant pairs. ${ }^{35}$ We can explain the nature and strength of association with anemia status when the explanatory variable is also measured in ordinal scale. On the other hand, the association is assessed by chi- square measure when the response categories are conditional on the nominal explanatory variables. For testing statistical significance of association in the bivariate analysis, gamma test and Chi-squared test of independence are used for ordinal and nominal explanatory variables respectively. Bivariate analysis results are reported in Table 1 . Under multivariate analysis, we consider proportional odds (PO) model. PO treats the categorical response as ordinal nature of the responses. PO generally has higher power for detecting effect of an explanatory variable as compared to models ignoring order. ${ }^{36}$ Analyses were conducted using a combination of packages "foreign" and "ordinal" in $\mathrm{R}$ version 3.4.3 as well as in IBM SPSS windows version 23.0.

\subsection{Results}

From the sampled children, $22.4 \%, 29.6 \%$ and $48 \%$ were severely or 
moderately anemic, mildly anemic, and non-anemic, respectively. Out of children who resided in rural areas, $30.6 \%$ were mildly anemic, and $23.00 \%$ were severely or moderately anemic. These figures were $27.1 \%$ and $21.1 \%$ for those children who resided in urban areas, respectively (Table 1). Gamma estimates show that there exist significant weak negative association with mother's age, wealth index, age of child and mother's as well as father's educational status respectively. Therefore, with the increase in birth order i. e first birth to above, children tend to move from not anemic to anemic category, while with the increase in parent's educational status, wealth index, mother's age and age of child, children tend to fall in 'not anemic' category. Place of residence, division, mother's anemia level, body mass index, breastfeeding status, recently suffering from fever or diarrhea, stunting, water and toilet facility are significantly associated with anemia status of the children, while no strong evidence of association is observed for other variables. The prevalence of anemia is highest in Barisal (26.4\%) and least in Dhaka (20.1\%), Rajshahi (19.3\%) and Khulna (21.1\%) division respectively (Table 1 ).

\subsection{Factors of severity levels of child anemia}

As shown in Table 2, children whose mother was anemic were 1.697 (OR $=1.697 ; 95 \%$ CI: 1.436-2.006; p-value < 0.0005) times more likely to be at higher anemia status as compared to children whose mother was not anemic. The estimate implied that children whose mother's age in the age range less than 20 years were 1.174 $(\mathrm{OR}=1.174 ; 95 \%$ CI: 0.891-1.546) times more likely to be at higher anemia status as compared to those in the age range of 30 years and above. Similarly, the likelihood of being at higher anemia status was 1.031 (OR $=1.031$; 95\% CI: 0.838-1.269) times higher for children in the age range of 20-29 years compared to those in the age range of 30 years and above. The result indicated that severely stunted children were 1.273 ( $\mathrm{OR}=1.273$; 95\% CI: 1.073-1.512; p-value < 0.0057) times more likely to be at higher anemia status as compared to nonstunted children. The estimate implied that children in the age range of 6-24 months were 3.49 (OR $=3.49$; 95\% CI: 2.785-4.383; p-value < 0.0005 ) times more likely to be at higher anemia status as compared to those in the age range of $36-59$ months. Similarly, the likelihood of being at higher anemia status was 1.233 (OR $=1.233$; 95\% CI: 0.976-1.557; p-value $<0.0782$ ) times higher for children in the age range of 24-36 months compared to those in the age range of 36-59 months. On the other hand, the odds of being at higher anemia status were higher for children whose households used non-improved source of drinking water $(\mathrm{OR}=1.328 ; 95 \% \quad \mathrm{CL}: 1.002-1.758$; $\quad$ value $=0.047$ ).

Children whose mother education level were at no-education, primary educational and Secondary education level as compared to Higher education were $1.32,1.122$, and 1.032 times more likely to be at higher anemia status. Children whose mothers' partners/husbands were at noeducation, primary educational and secondary education level as compared to Higher education were 1.042, 1.338, and 1.30 times more likely to be at higher anemia status.

For this model the deviance based chi-square test provided a chisquare value of 350.464 ( $\mathrm{p}$-value $<0.0005$ ) which implied that the model had good fit. Furthermore, the score chi-square test of parallelism showed that odds ratios appeared to have held constant across all cut-off points of childhood anemia status for the final model at $5 \%$ level (p-value $=0.461$ ). Since the parallel lines assumption was held, the interpretation of the result obtained by modeling severe or moderate anemic versus mild and mild versus not-anemic were the same. As per likelihood ratio test (LRT) comparing to null model, we see that place of residence (LRT: 1.164), breast feeding status (LRT: 0.404), recent diarrhea (LRT: 0.115), fever (LRT: 0.834), mother's age (LRT: 3.726) and her education (LRT: 1.846) have very less explanatory capability.
Table 2

Parameter estimates of related covariates in Ordinal Logistic Regression model.

\begin{tabular}{|c|c|c|c|c|c|c|}
\hline \multirow[t]{2}{*}{ Variable } & \multirow[t]{2}{*}{ Category } & \multirow[t]{2}{*}{ Estimate } & \multirow[t]{2}{*}{$\begin{array}{l}\text { Odds } \\
\text { Ratio }\end{array}$} & \multirow[t]{2}{*}{ p-value } & \multicolumn{2}{|c|}{$\begin{array}{l}95 \% \text { confidence } \\
\text { limits for OR: }\end{array}$} \\
\hline & & & & & Lower & Upper \\
\hline \multirow[t]{7}{*}{ Division } & Dhaka & - & - & - & - & - \\
\hline & Chittagong & 0.203 & 1.225 & 0.159258 & 0.924 & 1.625 \\
\hline & Barisal & 0.427 & 1.532 & $0.009391 *$ & 1.11 & 2.115 \\
\hline & Khulna & 0.344 & 1.411 & $0.033698 *$ & 1.027 & 1.939 \\
\hline & Rajshahi & 0.06 & 1.061 & 0.70979 & 0.775 & 1.453 \\
\hline & Rangpur & 0.358 & 1.43 & $0.020827^{*}$ & 1.056 & 1.938 \\
\hline & Sylhet & 0.054 & 1.056 & 0.716242 & 0.788 & 1.416 \\
\hline \multirow{2}{*}{$\begin{array}{l}\text { Type of } \\
\text { residence }\end{array}$} & Rural & - & - & - & - & - \\
\hline & Urban & 0.095 & 1.1 & 0.354191 & 0.899 & 1.346 \\
\hline \multicolumn{7}{|c|}{ Parental Characteristics } \\
\hline \multirow{4}{*}{$\begin{array}{l}\text { Mother's } \\
\text { educational } \\
\text { status }\end{array}$} & Higher & - & - & - & - & - \\
\hline & Secondary & 0.031 & 1.032 & 0.880617 & 0.688 & 1.556 \\
\hline & Primary & 0.116 & 1.122 & 0.61073 & 0.721 & 1.757 \\
\hline & $\begin{array}{l}\text { No } \\
\text { education }\end{array}$ & 0.278 & 1.32 & 0.260161 & 0.815 & 2.147 \\
\hline \multirow{4}{*}{$\begin{array}{l}\text { Father's } \\
\text { educational } \\
\text { status }\end{array}$} & Higher & - & - & - & - & - \\
\hline & Secondary & 0.265 & 1.303 & 0.113619 & 0.94 & 1.812 \\
\hline & Primary & 0.291 & 1.338 & 0.103693 & 0.943 & 1.902 \\
\hline & $\begin{array}{l}\text { No } \\
\text { education }\end{array}$ & 0.041 & 1.042 & 0.831217 & 0.714 & 1.526 \\
\hline \multirow[t]{3}{*}{ Mother 's Age } & $\begin{array}{l}30 \text { years } \\
\text { and above }\end{array}$ & - & - & - & - & - \\
\hline & $\begin{array}{l}20-29 \\
\text { years }\end{array}$ & 0.03 & 1.031 & 0.774346 & 0.838 & 1.269 \\
\hline & $\begin{array}{l}\text { Less than } \\
20 \text { years }\end{array}$ & 0.16 & 1.174 & 0.254338 & 0.891 & 1.546 \\
\hline \multirow{3}{*}{$\begin{array}{l}\text { Mother's body } \\
\text { mass index }\end{array}$} & Normal & - & - & - & - & - \\
\hline & $\begin{array}{l}\text { Under } \\
\text { weight }\end{array}$ & 0.209 & 1.232 & $0.031204^{*}$ & 1.019 & 1.49 \\
\hline & $\begin{array}{l}\text { Over } \\
\text { weight }\end{array}$ & 0.037 & 1.037 & 0.78554 & 0.796 & 1.348 \\
\hline \multirow[t]{3}{*}{ Wealth Index } & Rich & - & - & - & - & - \\
\hline & Middle & 0.14 & 1.15 & 0.289872 & 0.888 & 1.489 \\
\hline & Poor & 0.426 & 1.531 & $0.001035^{*}$ & 1.188 & 1.976 \\
\hline \multirow[t]{2}{*}{ Water facility } & Improved & - & - & - & - & - \\
\hline & $\begin{array}{l}\text { Non- } \\
\text { improved }\end{array}$ & 0.284 & 1.328 & $0.047695^{*}$ & 1.002 & 1.758 \\
\hline \multirow[t]{2}{*}{ Toilet facility } & $\begin{array}{l}\text { Non } \\
\text { improved }\end{array}$ & - & - & - & - & - \\
\hline & Improved & 0.038 & 1.039 & 0.698918 & 0.857 & 1.258 \\
\hline \multirow[t]{2}{*}{$\begin{array}{l}\text { Mother's anemia } \\
\text { level }\end{array}$} & $\begin{array}{l}\text { Not } \\
\text { anemic }\end{array}$ & - & - & - & - & - \\
\hline & Anemic & 0.529 & 1.697 & $5.52 \mathrm{E}-10^{*}$ & 1.436 & 2.006 \\
\hline \multicolumn{7}{|c|}{ Children Characteristics } \\
\hline \multirow{2}{*}{$\begin{array}{l}\text { Breastfeeding } \\
\text { status }\end{array}$} & No & - & - & - & - & - \\
\hline & Yes & 0.053 & 1.054 & 0.620505 & 0.855 & 1.3 \\
\hline \multirow[t]{3}{*}{ Age of child } & $\begin{array}{l}36-59 \\
\text { months }\end{array}$ & - & - & - & - & - \\
\hline & $\begin{array}{l}24-36 \\
\text { months }\end{array}$ & 0.21 & 1.233 & 0.07825 & 0.976 & 1.557 \\
\hline & $\begin{array}{l}06-24 \\
\text { months }\end{array}$ & 1.25 & 3.49 & $3.11 \mathrm{E}-27^{* *}$ & 2.785 & 4.383 \\
\hline \multirow{2}{*}{$\begin{array}{c}\text { Had diarrhea } \\
\text { recently }\end{array}$} & No & - & - & - & - & - \\
\hline & Yes & 0.064 & 1.066 & 0.726758 & 0.745 & 1.52 \\
\hline \multirow{2}{*}{$\begin{array}{l}\text { Had fever } \\
\text { recently }\end{array}$} & No & - & - & - & - & - \\
\hline & Yes & 0.078 & 1.081 & 0.365608 & 0.913 & 1.28 \\
\hline Stunting & No & - & - & - & - & - \\
\hline & Yes & 0.242 & 1.273 & $0.005719^{* *}$ & 1.073 & 1.512 \\
\hline
\end{tabular}

\section{Discussion}

Anemia among children aged 6-59 months is a major public health challenge in Bangladesh. Our results reveal that about $52 \%$ of the children aged 6-59 months nationally are anemic, which is consistent with previously reported national prevalence of anemia (51\%). ${ }^{29}$ The Chi-square test of parallelism, showed that the likelihood of being severely/moderately anemic as compared to being mildly/non-anemic and the likelihood of being severely/moderately/mildly anemic as compared to being non-anemic was similar for a given variable keeping 
all others among variables studied. Our analysis demonstrates that the Division, Mother's BMI, Wealth Index, Water facility, Mother's anemia level, Age of child, Stunting, have statistically significant associations with childhood anemia. The result indicated that severely/moderately stunted children were more likely to be severely/moderately anemic as compared to non-stunted. This result was consistent with the finding that stunting was associated with increased risk of anemia in children 6-59 months, and the anemia prevalence in children with stunting was 1.273 that of children with normal stature. ${ }^{37}$ The results also indicate that the likelihood of children in the age range of 6-24 months and 24-36 months being severely/moderately anemic was higher than those in the age range of 36-59 months, holding all other variables constant. The result of the study was consistent with the result of various studies. ${ }^{38-41}$ The odds of being severely/moderately anemic were higher for children whose households used non-improved source of drinking water which is agreed with the result that the occurrence of anemia was 1.68 times higher for children from households that consume untreated water as compared to those children from households that consume treated water. ${ }^{42}$ The results showed that, the odds of being severely/moderately anemic were higher for children whose mother's partners/husbands were illiterate. Relevant study showed that, education has an impact on healthcare and nutrition for children. ${ }^{43}$ The reasons behind this is educated partners have better health and nutrition knowledge and child rearing practices than uneducated ones. Education can both improve child health care and increase parent's income level which will enhance the quality of care and attention to the children. The results also demonstrate that higher child anemia status was more likely for children from anemic mothers compared to those from non-anemic mothers. This result was consistent with other finding that maternal anemia was associated with increased risk of anemia in children 6-59 months. ${ }^{42,44,45}$ Younger children and those with fever recently were also more likely to be anemic. Fever is common symptom of acute and chronic diseases which have been associated with lower hemoglobin levels as well as anemia. ${ }^{46}$ Children 6-59 months aged of the middle and poor class households had higher prevalence of anemia compared to the rich households, plausibly reflecting improved household nutritional status. ${ }^{47}$ This finding is also consistent with previous studies. ${ }^{48}$ Evidence shows that the odds of being severely/moderately anemic were higher for children whose mother's BMI was underweight or over weight compared to children whose mother's BMI was normal. The high prevalence of anemia in rural sectors especially in the southern division Barisal and northern division Rangpur can be linked to the fact that compare to Dhaka most of the areas in these regions are rural.

The strengths of this study included the use of a large, diverse and nationally representative sample. We also adjusted the findings for several confounding variables, particularly parental education level, and mother's current age, which strengthened the internal validity of the findings. The main limitation of this study is some variables did not get in a way we need. So, the confounding effect of some unmeasured variables cannot be controlled. Due to huge missing values corresponding to variables like antenatal care, iron pill intake of mothers during their during pregnancy, vitamin and iron deficiency measurements for both mother and children as well as the absence of data on other anemia-inducing comorbidities (malaria, schistosomiasis, and hookworm) we also didn't take into account them for our analysis. Therefore, the resulting residual confounding may affect the observed association of outcome variable and the determinant factors. Since the 2011 BDHS used one of the standardized methods, HemoCue rapid testing methodology, to measure $\mathrm{Hb}$ and an adjustment to sea-level equivalents was made as hemoglobin requirements differ substantially depending on altitude, misclassification of our outcome variables is likely to be minimal. However, we can not ignore the non-differential misclassification due to instrumental error and during data collection stage. Observer bias is also likely to be least as the interviewers were well trained, they used a standard questionnaire and they didn't have any prior knowledge of our research hypothesis. Moreover, there is room for misclassification in exposure due to information bias during data collection stage. Thus, any reader of this manuscript should take into account the above limitations.

\section{Conclusions}

The study revealed that Division, Father's education status, Wealth Index, Water facility, Toilet facility, Mother's anemia level, Breastfeeding status, Age of child and Stunting status of the children were the most important determinants of severity levels of child anemia in Bangladesh. Children with uneducated parents, poor family status, non-improve toilet facility, non-improve water facility, have significantly higher rates of anemia.

\section{Ethics approval}

We have used secondary dataset from the Demographic and Health Surveys (DHS) Program website (https://dhsprogram.com/data/). No ethics approval is required for this dataset.

\section{Funding}

This research did not receive any specific grant from funding agencies in the public, commercial, or not-for-profit sectors.

\section{Conflicts of interest}

None declared.

\section{Claiming interest}

Authors are not interested to face any claim about their study.

\section{Acknowledgement}

We would also like to show our gratitude to Demographic and Health Surveys (DHS) Program for providing data and also authors are debated to the Statistics Discipline, Khulna University for conducting this research activity successfully by making congenial work environment. Authors are confessing uncountable debts to authors of different articles are used in this study.

\section{Appendix A. Supplementary data}

Supplementary data to this article can be found online at https:// doi.org/10.1016/j.cegh.2019.06.009.

\section{References}

1. Hematol Ann. Anemia-still a Major Health Problem in Many Parts of the World. 42011 Apr; 2011 Apr:369-377. https://doi.org/10.1007/s00277-010-1144-5 Epub 2011 Jan 8.

2. Stevens GA, Finucane MM, De-Regil LM, et al. Global, regional, and national trends in haemoglobin concentration and prevalence of total and severe Anemia in children and pregnant and non-pregnant women for 1995-2011: a systematic analysis of population-representative data. Lancet Glob Health. 2013;1:e16-25.

3. World Health Organization. The Global Prevalence of Anemia. 2011; 2011.

4. Haas JD, Brownlie T. Iron-deficiency anemia: reexamining the nature and magnitude of the public health problem. In belmont conference: critical review of evidence that iron deficiency anemia causes reduced work capacity. J Nutr Geneva: WHO. 2001:676S-690S

5. Stoltzfus RJ. Defining iron-deficiency anemia in public health terms: a time for reflection. J Nutr. 2001 Feb 1;131(2):565S-567S.

6. McLean E, Cogswell M, Eglis I, Wojdyla D, de Benoist B. World- wide prevalence of anaemia, WHO vitamin and mineral nutrition information system, 1993-2005. Publ Health Nutr. 2009;12:444-454.

7. Worldwide Prevalence of Anemia 1993-2005. WHO Global Database on Anemia Geneva World Health Organization; 2008.

8. Anemia in Bangladesh: a longstanding, preventable public health problem. . 
Available from:https://www.researchgate.net/publication/315053693_Anemia_in_ Bangladesh_A_Longstanding_Preventable_Public_Health_Problem , Accessed date: 24 September 2017.

9. Nam UV. Transforming Our World: The 2030 Agenda for Sustainable Development. New York, NY, USA: Division for Sustainable Development Goals; 2015 Apr.

10. Unicef. A Post 2015 World Fit for Children: An Agenda for Every Child 2015. New York, NY: UNICEF; 2015

11. Millennium Development Goals. Bangladesh Progress Report 2015. General Economics Division (GED). Bangladesh Plannning Commission. Government of the People's Republic of Bangladesh; September 2015.

12. Smith R. The clinical and economic burden of anemia. Am J Manag Care. 2010;16(Suppl):S59-S66.

13. Levy A, Fraser D, Katz M, Mazor M, Sheiner E. Maternal anemia during pregnancy is an independent risk factor for low birth weight and preterm delivery. Eur J Obstet Gynecol Reprod Biol. 2005;122:182-186.

14. WHO. Iron Deficiency Anaemia: Assessment. Prevention and Control. A Guide for Programmemanagers. Geneva: World Health Organization; 2001:114.

15. Benoist BD, McLean E, Egli I, Cogswell M, eds. Worldwide Prevalence of Anaemia 1993-2005: WHO Global Database on Anaemia. Geneva, Switzerland: World Health Organization; 2008 .

16. Khan JR, Awan N, Misu F. Determinants of anemia among 6-59 months aged children in Bangladesh: evidence from nationally representative data. BMC Pediatr. 2016 Dec;16(1):3.

17. O'Donnell A, Carmuega ES, Durán P. Preventing iron deficiency in infants and preschool children in Argentina. Nutr Rev. 1997;55:189-194.

18. Nestel P, Melara A, Rosado J, Mora JO. Vitamin A deficiency and anemia among children 12-71 months old in Honduras. Rev Panam Salud Publica. 1999;6:34-43.

19. Romani SAM, Lira PIC, Batista Filho M, Sequeira LÃ.S, Freitas CLC. Anemiasempréescolares: diagnóstico, tratamento e avaliaçãoem Recife-PE, Brasil. Arch Latinoam Nutr. 1991;41:159-167.

20. Kawo KN, Asfaw ZG, Yohannes N. Multilevel analysis of determinants of anemia prevalence among children aged 6-59 Months in Ethiopia: classical and bayesian approaches. Anemia. 2018;2018.

21. Kounnavong S, Sunahara T, Hashizume M, et al. Anemia and related factors in preschool children in southern rural Lao peoples democratic republic. Trop Med Health. 2011;39:95-103.

22. Konstantyner T, Oliveira TCR, AguiarCarrazedoTaddei JA. Risk factors for anaemia among Brazillian infants from the 2006 national demographic health survey. Anaemia. 2012;2012:850681.

23. Ngwira A, Kazembe LN. Bayesian random effects modelling with application to childhood anaemia in Malawi. BMC Public Health. 2015;15:161.

24. Cornet M, Hesran J, Fievet N, et al. Prevalence and risk factors for anaemia in young children in southern Cameroon. Am J Trop Med Hyg. 1998;58(5):606-611.

25. Tengco LW, Solon PR, Solon JA, et al. Determinants of anemia among preschool children in Philippines. J Am Coll Nutr. 2008;27(2):229-243.

26. Parischa S, Black J, Muthayya S, et al. Determinants of anaemia among young children in rural India. Pediatrics. 2010;126:e140.

27. Cosmas S. Socio Demographic Determinants of AnaemiaAmong Children Aged 6-59 Months in Mainland Tanzania. Maastricht University; 2011. Available from http:// www.hdl.handle.net/1942/12761, Accessed date: 20 February 2013.

28. Dey S, Goswami S, Dey T. Identifying predictors of childhood anaemia in north-east India. J Health Popul Nutr. 2013;31(4):462-470.

29. National Institute of Population Research and Training (NIPORT), Mitra and
Associates, ICF International. Bangladesh Demographic and Health Survey 2011. Dhaka: Bangladesh and Calverton. Maryland, USA: NIPORT, Mitra and Associates, ICF International; 2013.

30. Rahman Khan1 Jahidur, Awan Nabil, FarjanaMisu. Determinants of anemia among 6-59 months aged children in Bangladesh: evidence from nationally representative data; Khan et al. BMC Pediatr. 2016;16:3. https://doi.org/10.1186/s12887-015 0536-z.

31. KindieFentahunMuchie. Determinants of severity levels of anemia among children aged 6-59 months in Ethiopia: further analysis of the 2011 Ethiopian demographic and health survey. Muchie BMC Nutr. 2016;2:51. https://doi.org/10.1186/s40795016-0093-3.

32. McCullagh P. Regression models for ordinal data. J R Stat Soc Ser B Stat MethodoL 1980;42(2):109-142

33. Peterson B, Harrell FE, Petersont B. Partial proportional odds models for ordinal response variables. J R Stat Soc Ser C Appl Stat. 1990;39(2):205-217.

34. Greenland S. Alternative models for ordinal logistic regression. Stat Med. 1994:13(16):1665-1677.

35. Goodman LA, Kruskal WH. Measures of association for crossclassifications. J Am Stat Assoc. 1954;49:732-764.

36. Agresti A. Analysis of Ordinal Categorical Data. John Wiley \& Sons; 2010.

37. Cotta RMM, de Cc OF, Magalhaes KA, et al. Social and biological determinants of iron deficiency anemia. Cad Saúde Pública. 2011;27(2):S309-S320.

38. Gebreegziabiher G, Etana B, Niggusie D. Determinants of anemia among children aged 6-59 Months living in KilteAwulaeloWoreda, northern Ethiopia. Anemia. 2014 https://doi.org/10.1155/2014/245870.

39. Cardoso MA, Scopel KKG, Muniz PT, Villamor E, Ferreira MU. Underlying factors associated with anemia in Amazonian children: a population-based, cross-sectional study. PLoS One. 2012;7(5):e36341

40. Oliveira MAA, Osório MM, Raposo MC. Socioeconomic and dietary risk factors for anemia in children aged 6 to 59 months. J Pediatr. 2007;83(1):39-46.

41. Konstantyner T, Roma Oliveira TC, De AguiarCarrazedoTaddei JA. Risk factors for anemia among Brazilian infants from the 2006 national demographic health survey. Anemia. 2012. https://doi.org/10.1155/2012/850681.

42. Cotta RMM, de Cc OF, Magalhaes KA, et al. Social and biological determinants of iron deficiency anemia. Cad Saúde Pública. 2011;27(2):S309-S320.

43. Leal LP, Batista Filho M, de Lira PIC, Figueiroa JN, Osório MM. Prevalence of anemia and associated factors in children aged 6-59 months in Pernambuco. Northeast. Brazi Rev. de Saúde Pública. 2011;45(3):457-466.

44. Souza LG, Santos RV, Carvalho MS, Pagliaro H, Flowers NM, Coimbra Jr CEA. Demography and health of the xavante Indians from Central Brazil. Cad Saúde Pública. 2011;27(10):1891-1905http://doi.org/10.1590/S0102311X2011001000003.

45. McSweeney K, Arps SA. A "demographic turnaround": the rapid growth of indigenous populations in lowland South America. Lat Am Res Rev. 2005;40(1):3-29.

46. Konstantyner T, Oliveira TCR, AguiarCarrazedoTaddei JA. Risk factors for anaemia among brazillian infants from the 2006 national demographic health survey. Anaemia. 2012;2012:850681.

47. Singh MB, Fotedar R, Lakshminarayana J, Anand PK. Studies on the nutritional statu of children aged 0-5 years in a drought-affected desert area of Western Rajasthan, India. Publ Health Nutr. 2006;9(8):961-967.

48. Muniz PT, Castro TG, Araújo TS, et al. Child health and nutrition in the Western Brazilian Amazon: population-based surveys in two counties in Acre State. Cad Saúde Pública. 2007 Jun;23(6):1283-1293. 